\title{
Integrating Global, Ethical, And Multicultural (GEM) Issues Into The Manufacturing Engineering Senior Design Projects
}

\author{
Bahram Asiabanpour, Ph.D., CMfgE, Texas State University, USA
}

\begin{abstract}
To satisfy manufacturing engineering accreditation requirements, to assist students in finding and retaining jobs, and to provide equal learning opportunities, global, ethical, and multicultural (GEM) topics were added to the senior design project course. Diverse interactive tools and methods were used to cover the topics and a multifaceted method was used to evaluate the effectiveness of the added topics. Results showed generally significant improvement in students' awareness of the GEM topics.
\end{abstract}

Keywords: Global, Ethical, And Multicultural (GEM) Issues; Manufacturing Engineering Accreditation Requirements; Engineering Education

\section{INTRODUCTION}

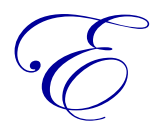

ngineering undergraduate students usually summarize their technical skills in the form of the capstone senior design projects. The purpose of these projects is introducing the students to real- world problems and engaging them in hands-on projects. In these projects students not only utilize a variety of methods and skills that they have acquired in other courses, but also learn and experience new skills such as design and manufacture under time and budget constraints, project management, teamwork, creativity, and communication skills, that cannot be easily taught in the typical classroom setting.

\section{MFGE Senior Design Course Format}

At Texas State University-San Marcos, Manufacturing Engineering is an ABET (Accreditation Board for Engineering and Technology) accredited program that started in 1999. The senior design course (course catalog name: Concurrent Process Engineering), was developed and has been taught for ten years by the same instructor (the author) in the form of a one-semester course. Classes meet twice a week, with 2 hours of lecture and 3 hours of lab/project work. However, students usually need to spend additional hours working on their projects outside of the classroom setting. Class size is usually between 15 and 25 students. Major topics that are covered in the lecture sections include: Safety and Manufacturing Processes Practice, Concurrent Engineering Concept, Identifying Customer Needs, Innovation and Creativity, Teamwork and Project Management, Defining Product Specifications and Quality Function Deployment (QFD), Concept Generation and Selection, Design for X (manufacturing, assembly, safety, environment, etc.), Failure Mode and Effects Analysis (FMEA), and Business Plan.

Each project is assigned to a team of three or four students to work on during the semester according to the predefined multistage assignments (see example in Appendix A). Each project usually has a technical/financial industry sponsor that provides students with a clear need/problem statement at the beginning of the semester and feedback on the team's progress during the semester for every step of the project. Sponsors vary from private individuals to small local industries to large international companies (e.g., Toyota). 
The course grading system considers active class participation, homework (individual/weekly), assignments (team/weekly), quizzes (individual/occasional), presentations (team/biweekly), final exams (individual/end of the semester), and final projects (team/one submission). Approximately $50 \%$ of the final grade is assigned to the final project including prototype, report, and presentation. Sponsor input about the team's performance is an important consideration for the team project grade. A panel of experts consisting of engineering faculty and industry experts observe and judge the final presentations of the projects and while they select the best project, they also provide technical feedback to individual teams and the class overall. Figure 1 shows the multilevel evaluation system of the students' learning.

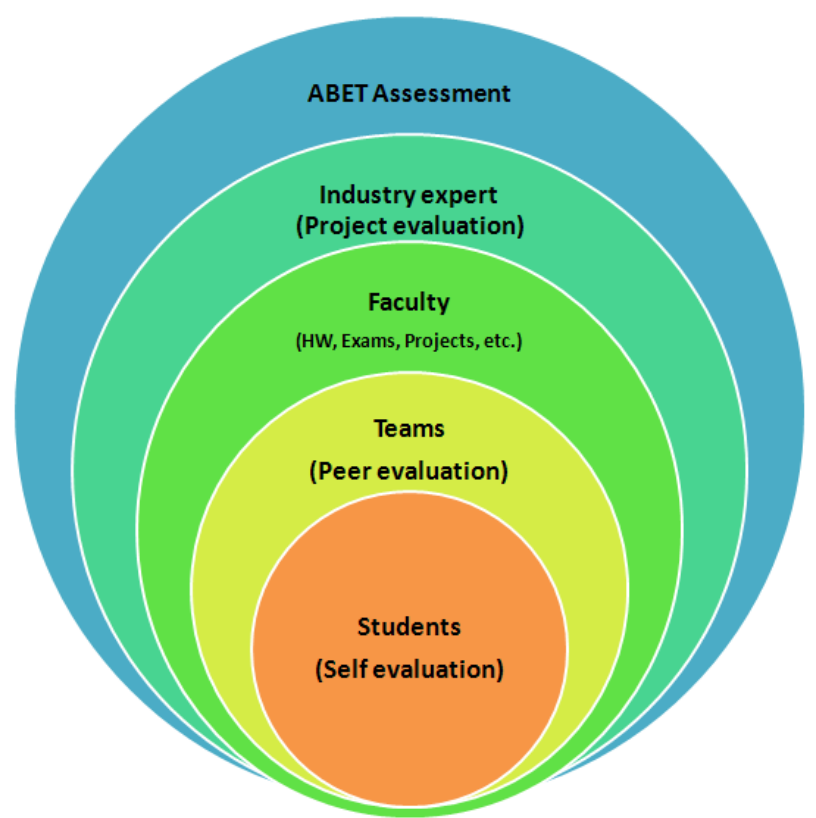

Figure 1: Multi-Level Students’ Learning Evaluation System

\section{Reasons For Injecting The New Topics Into The Course}

This capstone senior design class is already an overloaded course that, based on the students' comments, instructor assessment, and external evaluators, is taking more time than a typical three credit hours course. However, there are a few necessities that led us to add new global, ethical, and multicultural (GEM) topics to this course.

\section{ABET Requirement}

The senior design course is a key course for the ABET accreditation of the manufacturing engineering program. In the latest ABET visit, review, and report about our school, this course was identified as one of four manufacturing engineering program strengths by the ABET accreditation reviewers. This course covers 7 out of 11 students' outcome (also known as a-k), (typically one or two for other courses), and 2 out of 5 program-specific criterion 1 items. One of the students' outcome items, like other outcomes, that needs to be addressed by at least two courses for the ABET accreditation is "an understanding of professional and ethical responsibility." The senior design course is one of the courses selected to cover and measure this outcome.

\section{Finding Jobs, Retaining Jobs, And Progressing In A Job}

One of the common deficiencies that has been reported for new graduates by the industry sectors is the mismatch between graduate skills versus industry needs (i.e., soft skills) (Eggert, R. J., 2003). Also, according to Howe, W. (2012) the number one reason why people are fired from their jobs is because they cannot get along with others. Lack of understanding of cultural differences, global perspectives, and ethical issues can play a key role in 
problems in interactions between individuals. These students' deficiencies need to be addressed before such situations arise.

\section{Learning Opportunity For All}

Over the years of teaching this course, the author has noticed that while a project is conducted by a team and presumably with all members having an equal vote, it appears that often the team is dominated by one or two individuals who are more skillful, have a better GPA, and/or are older than other teammates. While this seems to be natural and probably comfortable for everyone, it causes us to question whether we have been able to fully engage everyone in the learning process. Some of the topics seem to be learned through assigning a responsibility (e.g., team leadership) to a specific person. That is probably challenging for certain individuals but they will not gain those skills otherwise. It was decided that certain team tasks (e.g., leadership role) be assigned to the individuals that have not been known to take such roles in their previous classes.

\section{The Focus Of This Research}

The focus of this research is (a) to design and implement a system that injects the GEM thinking into the students' minds as a lifelong learning and (b) create a method to evaluate and measure the effectiveness of the method that, while it is engaging, is not off the topic of the product design procedure and is not diverting students' attention from their projects.

\section{METHODOLOGY}

As suggested by Larke, P. (2012), diverse tools and methods were employed to cover the topic and measure its effectiveness.

\section{Teaching}

To implement the GEM system, a new two-hour lecture time slot was added to this course. The lecture included a formal presentation covering key topics of GEM, a few videos related to GEM, two case study videos (i.e., Morales case and Apple factory in China), a guest speaker (an alumnus working in China), and an in-class culture difference game. All activities included in-class discussions.

\section{Team Formation}

Students formed the teams based on their favorite projects and teammates. However, among three or four members on each team, the instructor selected the team leader. The selection criterion was basically based on the previous information about each individual. On each team the one who had never served as the team leader in the previous courses was selected as the team leader (all students in this class would have taken at least two other required courses with the same instructor, both of them also project-based courses). The assumption was that such students usually voluntarily or involuntarily forgo the project leadership opportunities. Compared to other team members, team leaders have extra responsibility for communicating with the sponsors, submitting team assignments, and organizing team meetings.

\section{Evaluation}

Different evaluation methods were considered to assess the effectiveness of the teaching section.

Quizzes

Two quizzes_(in the form of pre-post) with diverse questions on the GEM topics were designed and given. The method was inspired by the Ethnic Literacy Test by Cushner, K. (2002) that follows a "test, provide info, and test again" method. There was a three-week gap between the pre and post quizzes. Each question contained an obvious or hidden GEM point which was discussed between the two quizzes. Example: 
Question: If you are asked to order only one type of pizza for the student organization meeting, what type of pizza do you choose?

Discussion point: Many individuals, because of their religion, diet, culture, or personal preference, may be restricted to limited choices.

Hidden point: It is preferred to consider and engage ALL rather than going by majority vote in such cases.

Homework

Also in the form of homework, students' critical thinking and self-evaluation were tested. For this Homework, students were graded and commented on their own pre-post quizzes, as well as the case study videos, and also answered a few extra questions about their life experience of the GEM topics.

\section{Examinations}

An Examination question related to the GEM topics was included in the final exam questions (multiple choice questions). Finally, teams were asked that at least in one slide in their final project presentation they address the GEM issues that they faced in their team or project.

\section{RESULTS}

\section{Quiz (Self-Assessment Of Progress In Pre-Post Quiz) And Homework (Critical Thinking)}

Fourteen out of 15 students in this class took both pre-post quizzes and participated in the GEM topic lecture. Appendix B shows their self-assessment of their awareness on the GEM questions in the form of pre-post assessment graphs and $\mathrm{t}$ test for Alpha $=0.1$ and Alpha $=0.002$. Based on the results, the average showed improved awareness while statistically most of the improvements were significant.

In their Homework, students were asked to comment on their GEM awareness progress in the pre-post quiz and highlight their weak areas. In this Homework, students were also given a choice to answer one of two questions: comment on their life experience of a GEM case or introduce a new question to measure people's knowledge of GEM. Almost the entire class answered the first question, personal life experience of GEM (a few students answered both). The students' comments were then grouped and shared with all (Appendix C).

\section{Final Exam Question}

One out of 25 questions on the final multiple choice exam was assigned to a GEM-related question. 100\% of students answered this question correctly. This was the case for only one other question. Overall class average for the exam was $73 \%$.

\section{Team Leader Assignment}

Team leaders for the teams were assigned by the instructor. The results were contradictory for different teams. We observed two good moral and responsive leaders in two cases, while we faced overwhelmed students and unhappy teammates and sponsors for the other two teams.

\section{Project Reflection}

Teams were asked to show at least one slide in their final presentation about the GEM issues they faced during their projects or in their product design considerations. All four projects highlighted design considerations they considered for diverse users (male/female, different body sizes, etc.) No controversial or human related issues were reported. 


\section{CONCLUSIONS}

There were noticeable different issues that emerged during the implementation and testing of the GEM topics. One issue was the importance of class participation. For example, although it cannot be generalized, one student missed class on the day the GEM topic was covered. Afterward, he read the handout and watched the videos and took the pre-post quiz on his own. His answers for the pre-post quiz questions were almost identical and he could not respond to the critical thinking HW assignment by commenting on the situations. Therefore, missing the in-class discussion probably had a major effect on his case.

Another issue was noticed in the critical thinking homework. In that homework, students had a choice to answer one of two questions: comment on their life experience of a GEM case or introduce a new question to measure people's knowledge of GEM. The entire class preferred to comment on their own life experiences. There may be different reasons for this, such as whether the introduction of a new question to measure GEM skills is a hard task or students had untold stories that they wanted to share. In any event, their stories were very interesting and diverse, as presented in Appendix C.

Team leader assignments were controversial. The sample size was small (only four teams); therefore, the results cannot be used to draw any statistical conclusions. However, one thing is obvious: that some students were not in a position to lead a team. They were a burden for their team as the teammates had to do the follow-ups, meeting arrangements, and communications with the sponsors and faculty while the team leader was absent or not performing properly. Overall, the addition of the GEM topics to this course seems to be appropriate, timely, and successful. Some variation of topics and activities may be considered for upcoming semesters.

\section{AUTHOR INFORMATION}

Bahram Asiabanpour, Ph.D., is an Associate Professor of Manufacturing Engineering and a Certified Manufacturing Engineer (CMfgE). He has served at Texas State since 2003. He has two years of work experience in a car design company in tool design and CAD/CAM positions. He has published several journal and conference papers in the areas of rapid prototyping and rapid tooling process. He has also enlisted the support of local industries and government agencies in his teaching and research activities. He is the director of the Rapid Product and Process Development (RPD) laboratory at Texas State University. Bahram Asiabanpour, Ph.D., CMfgE, Ingram School of Engineering, Texas State University, San Marcos, Texas 78666, USA.

Email:ba13@txstate.edu

\section{REFERENCES}

1. Cushner, K. (2002), "Human Diversity in Action - Developing Multicultural Competencies for the Classroom," McGraw-Hill.

2. Eggert, R. J. (2003), "Engineering Design Education: Surveys of Demand and Supply," Proceedings of the 2003 American Society for Engineering Education Annual Conference \& Exposition, Nashville, TN.

3. Howe, W. (2012), "Best Practices in Multicultural Curriculum Transformation," Workshop, Texas State University-San Marcos, TX.

4. Larke, P. (2012), "Culturally Responsive Teaching in Higher Education: What Professors Need to Know," Workshop, Texas State University-San Marcos, TX. 


\section{APPENDIX}

Appendix A: An example of the different steps for a typical project

Gathering data and observation




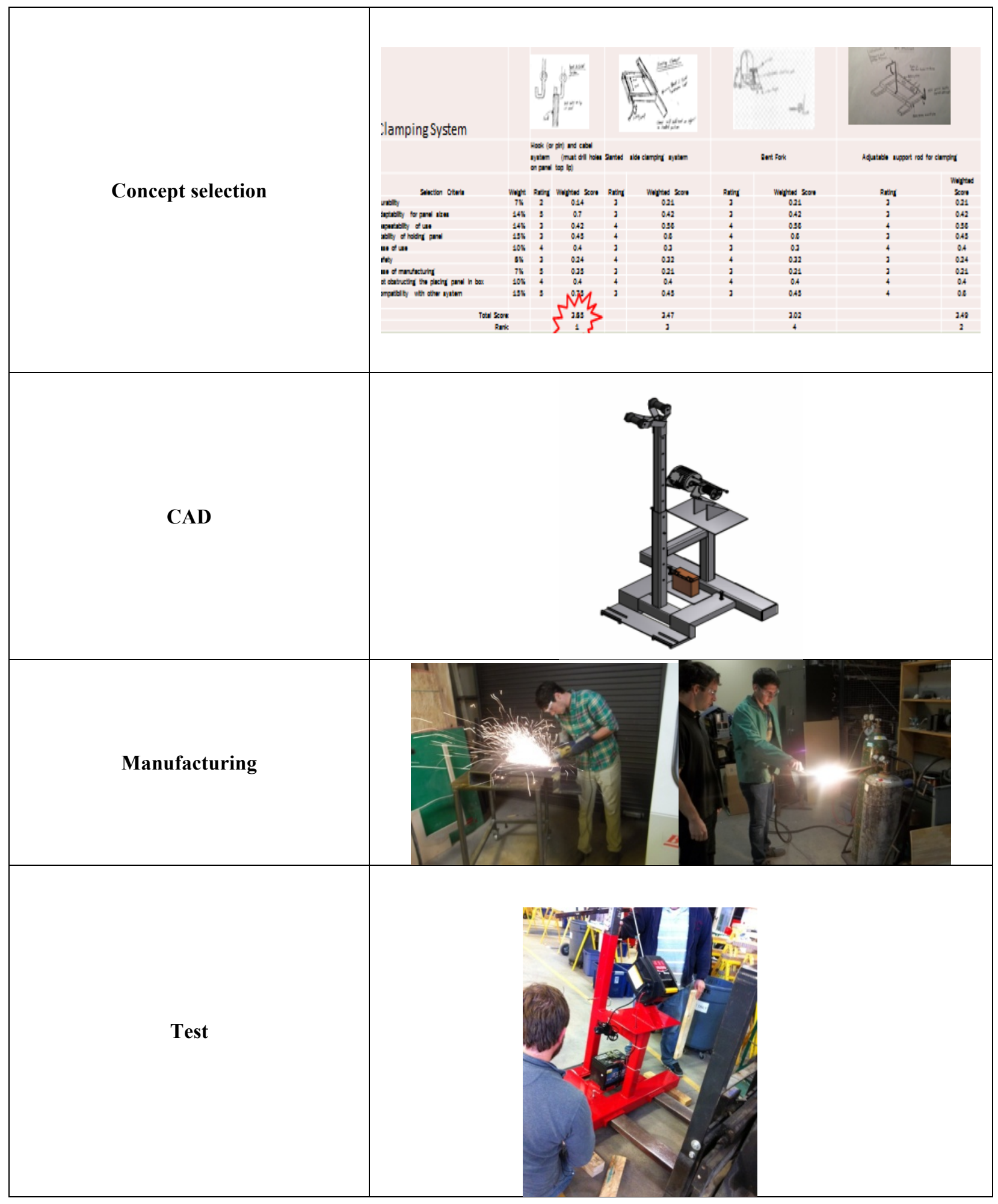


Appendix B: Students self-assessment on Pre-Post quiz questions

In this section, students evaluated their awareness and knowledge on the GEM related questions.

Q1: Draw your home

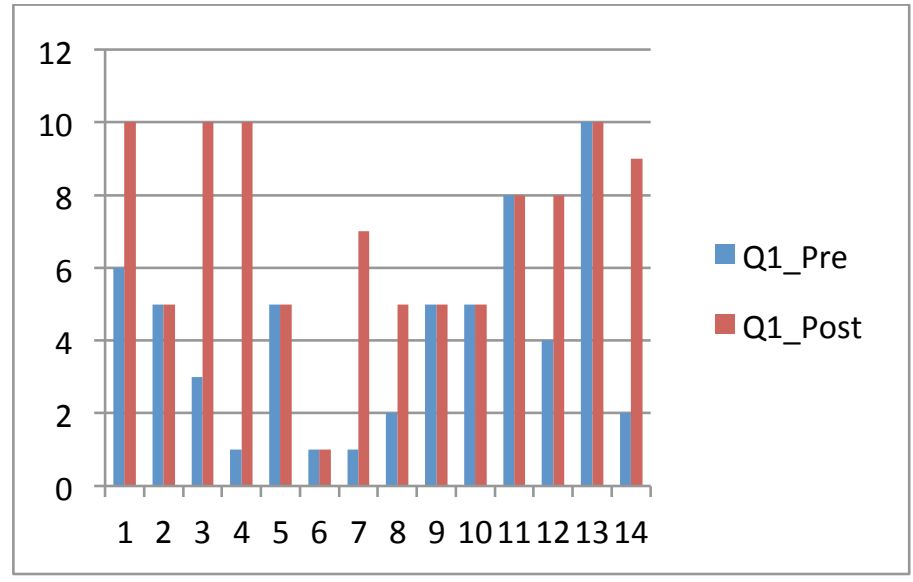

\begin{tabular}{|rc|}
\hline Average $=$ & 2.86 \\
Stdev $=$ & 3.30 \\
$\mathrm{~T} 13, .95=$ & 1.77 \\
$\mathrm{LB}=$ & 1.30 \\
$\mathrm{UB}=$ & 4.42 \\
\hline Average $=$ & 2.86 \\
Stdev $=$ & 3.30 \\
$\mathrm{~T} 13, .999=$ & 3.85 \\
$\mathrm{LB}=$ & -0.54 \\
$\mathrm{UB}=$ & 6.25 \\
\hline
\end{tabular}

Q2: Order pizza for student organization

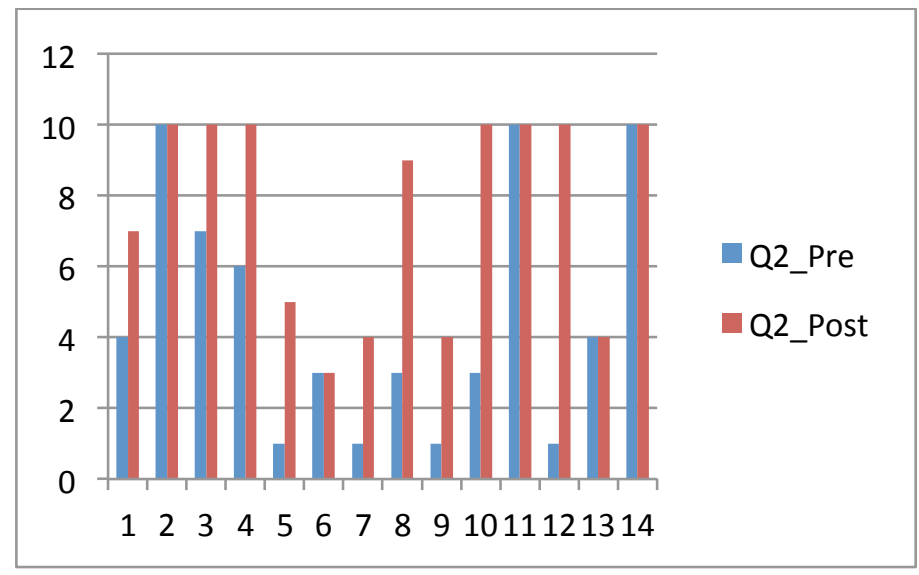

\begin{tabular}{|rl|}
\hline Average $=$ & 3.00 \\
Stdev $=$ & 2.88 \\
$\mathrm{~T} \mathrm{n}-1, .95=$ & 1.77 \\
$\mathrm{LB}=$ & 1.64 \\
$\mathrm{UB}=$ & 4.36 \\
\hline \\
Average $=$ & 3.00 \\
$\mathrm{Stdev}=$ & 2.88 \\
$\mathrm{~T} 13, .999=$ & 3.85 \\
$\mathrm{LB}=$ & 0.03 \\
$\mathrm{UB}=$ & 5.97 \\
\hline
\end{tabular}

Q3: What do you see (people's pictures)

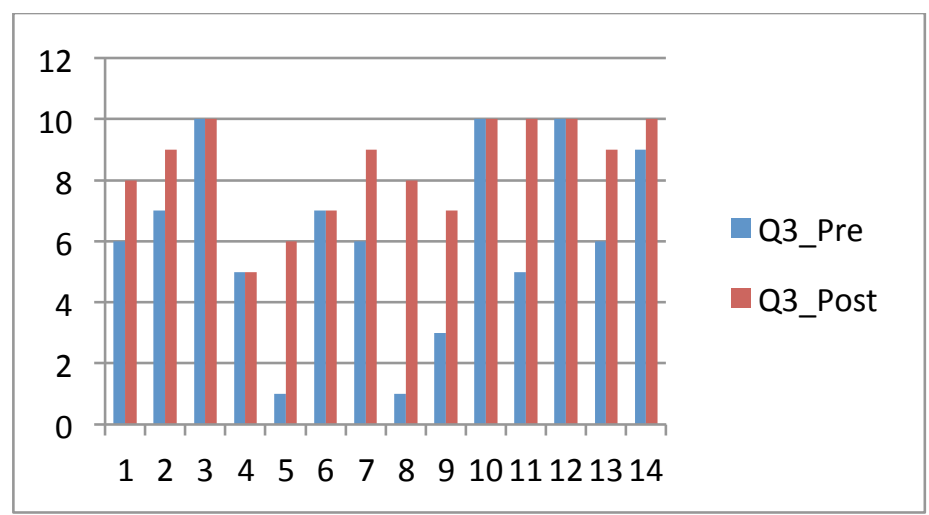

\begin{tabular}{|rc|}
\hline Average $=$ & 2.29 \\
Stdev $=$ & 2.30 \\
$\mathrm{~T} \mathrm{n}-1, .95=$ & 1.77 \\
$\mathrm{LB}=$ & 1.20 \\
$\mathrm{UB}=$ & 3.37 \\
\hline Average $=$ & 2.29 \\
Stdev $=$ & 2.30 \\
$\mathrm{~T} 13, .999=$ & 3.85 \\
$\mathrm{LB}=$ & -0.08 \\
$\mathrm{UB}=$ & 4.65 \\
\hline
\end{tabular}


Q4: What country do you see in this picture?

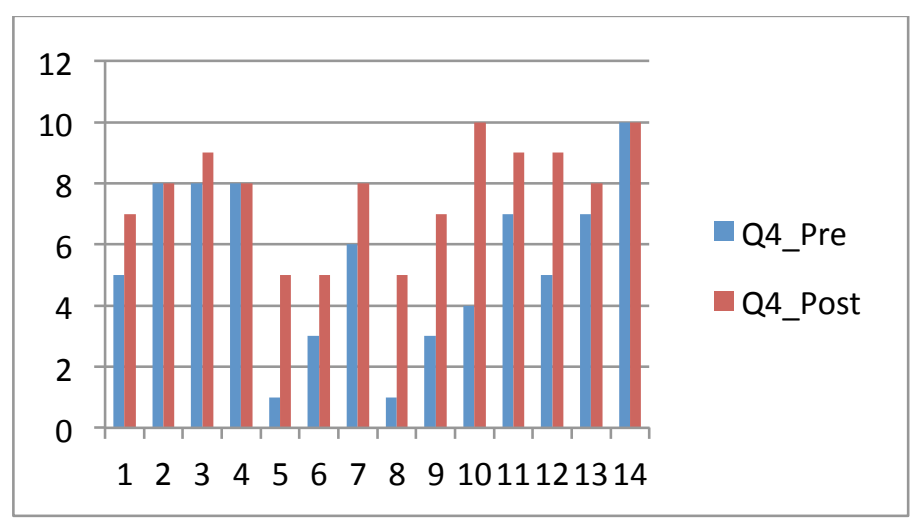

\begin{tabular}{|rl|}
\hline Average $=$ & 2.29 \\
Stdev $=$ & 1.86 \\
$\mathrm{~T} \mathrm{n}-1, .95=$ & 1.77 \\
$\mathrm{LB}=$ & 1.41 \\
$\mathrm{UB}=$ & 3.16 \\
\hline Average $=$ & 2.29 \\
Stdev $=$ & 1.86 \\
$\mathrm{~T} 13, .999=$ & 3.85 \\
$\mathrm{LB}=$ & 0.37 \\
$\mathrm{UB}=$ & 4.20 \\
\hline
\end{tabular}

Q5: Ability in saying hello in different languages

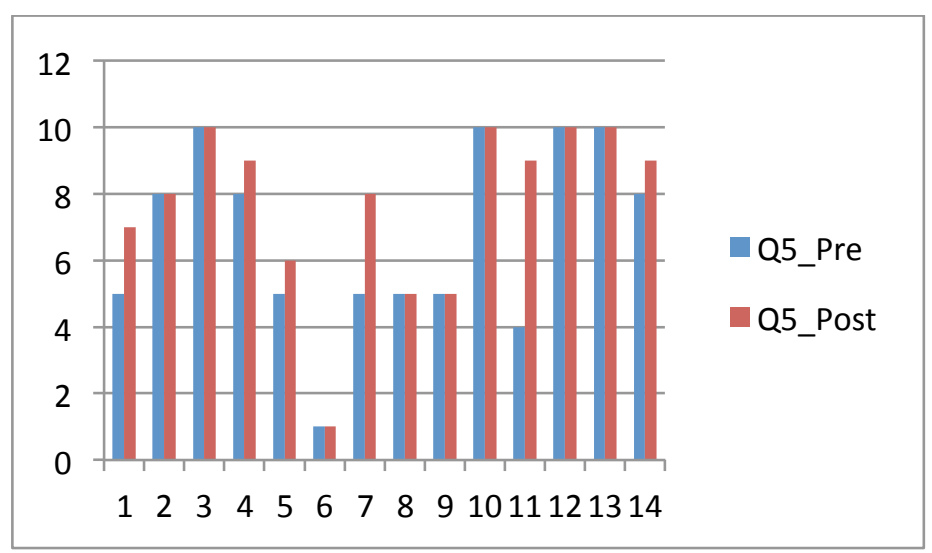

\begin{tabular}{|rc|}
\hline Average $=$ & 0.93 \\
Stdev $=$ & 1.49 \\
$\mathrm{~T} \mathrm{n}-1, .95=$ & 1.77 \\
$\mathrm{LB}=$ & 0.22 \\
$\mathrm{UB}=$ & 1.63 \\
\hline Average $=$ & 0.93 \\
$\mathrm{Stdev}=$ & 1.49 \\
$\mathrm{~T} 13, .999=$ & 3.85 \\
$\mathrm{LB}=$ & -0.61 \\
$\mathrm{UB}=$ & 2.46 \\
\hline
\end{tabular}

Q6: How to shake hand

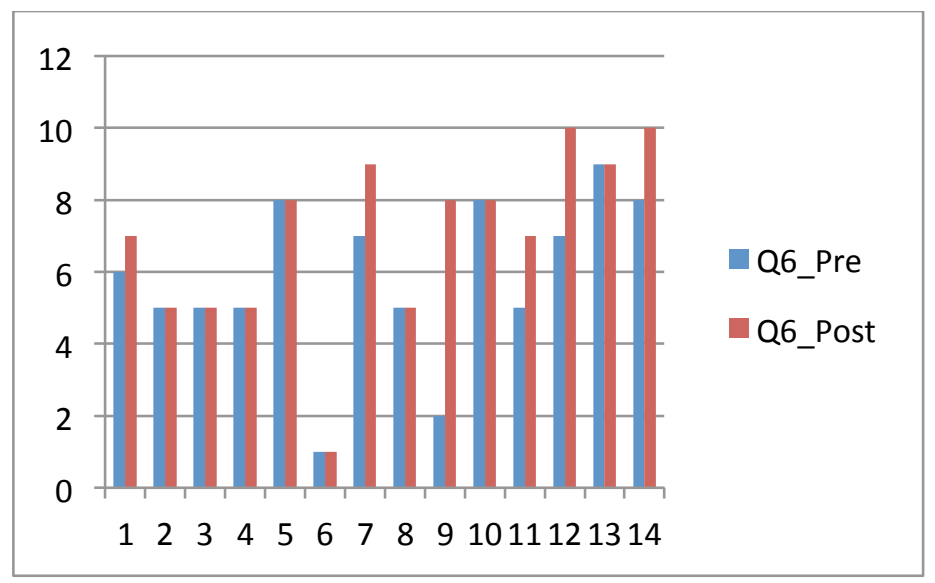

\begin{tabular}{|rc|}
\hline Average $=$ & 1.14 \\
Stdev $=$ & 1.75 \\
$\mathrm{~T} \mathrm{n}-1, .95=$ & 1.77 \\
$\mathrm{LB}=$ & 0.32 \\
$\mathrm{UB}=$ & 1.97 \\
\hline Average $=$ & 1.14 \\
$\mathrm{Stdev}=$ & 1.75 \\
$\mathrm{~T} 13, .999=$ & 3.85 \\
$\mathrm{LB}=$ & -0.66 \\
$\mathrm{UB}=$ & 2.94 \\
\hline
\end{tabular}


Appendix C: Students answers to life experiences of a GEM case

Question: Give an example that you have experienced or are experiencing that you or certain group or individual's right are violated or ignored just because you/they are in minority or different.

- I'm not sure if I agree but my old roommate was gay and felt that not being allowed to get married was a violation of his rights.

- During a club meeting for an outside organization, I experienced a member saying offending comments to another organization for no apparent purpose other than to offend the members of that club. This action was taken towards a minority group and action was taken by the group to correct the situation.

- One time in high school, I was almost tripped by some jerk and then he got in my face, and nobody didn't even object to what was happening, and then when he was in my face, I grabbed his face and slammed him against the lockers and then everybody started to object.

- I know from personal experience that right after high school that I did not own a car while I worked and raised money. I was also pursuing education elsewhere. Many people kept on making remarks to me about not having a car sometimes to the point of chanting at times without even arguing. Many of these remarks were not right.

- I recently was involved in a situation where I was denied the opportunity to a normal, professional interview, based solely on the fact that I was a female. The interviewer told me that she did not want to hire a girl, because it would cause a distraction in the workplace.

- The behavior of the City of San Marcos in illegally ticketing students for parking violations (when it clearly contradicts the city's own written laws) and collecting money due to the students' lack of understanding of parking laws and municipal code.

- While I was an intern at a company, I found out that myself and 2 (female) other interns from TXSTATE got pay less than the male interns from A\&M. I believe that this is a discrimination against school and gender.

- While I come from a position of great privilege due to my race and gender, the only (small) violation of my rights I've experienced due to being a minority happened to be when I was a practicing vegetarian. I was a vegetarian for 10 years, and frequently when eating out with co-workers vegetarian options were not considered 